\title{
Chemical and kinetic study of the lipoproteins in abetalipoproteinaemic plasma
}

\author{
JAMES SHEPHERD, MURIEL CASLAKE, ELIZABETH FARISH, AND \\ ADAM FLECK \\ From the University Departments of Biochemistry, the Royal and Western Infirmaries, and the University \\ Department of Medical Cardiology, the Royal Infirmary, Glasgow G4 OSF, UK
}

SUMMARY Abetalipoproteinaemic plasma lipoproteins were fractionated by molecular sieve chromatography into two classes on the basis of size. Each class had the same chemical and immunochemical composition and seemed to be interconvertible in vitro, presumably as a result of aggregation/disaggregation. The low levels of circulating apolipoprotein A-I found in abetalipoproteinaemic subjects have been shown by kinetic analysis to result from reduced synthesis of the apoprotein and not from increased catabolism or redistribution between vascular and extravascular compartments.

\begin{abstract}
Abetalipoproteinaemia, a rare autosomal recessive condition (Frézal et al., 1961) first described by Bassen and Kornzweig (1950), is characterised clinically by severe hypolipidaemia, acanthyocytosis, retinitis pigmentosa, cerebellar ataxia, and fat malabsorption (Fredrickson et al., 1967; Sturman, 1968; Fredrickson et al., 1972; Kayden, 1972). The fundamental molecular abnormality of the disease seems to be complete absence of immunologically detectable circulating apolipoprotein B (ApoB), which is the major protein of low density lipoproteins (LDL) and a minor but evidently essential component of very low density lipoproteins (VLDL) and chylomicra. Consequently the plasma of affected individuals is devoid of these lipoproteins. In addition the concentration and mean hydrated density of the remaining high density lipoproteins (HDL) are reduced (Jones and Ways, 1967) and their apoprotein content altered (Kostner et al., 1974).

Two distinct particulate species of abetalipoproteinaemic lipoproteins have been found by electron microscopy (Scanu et al., 1974). The predominant species was similar in morphology and mean diameter to normal HDL. A second, minor lipoprotein was isolable in the density range of normal LDL. Most particles of this type had an unusual packing arrangement, giving the mosaic appearance initially described by Forte and Nichols (1972). Earlier these
\end{abstract}

Received for publication 19 October 1977 authors had shown that abetalipoproteinaemic plasma contained lipoprotein particles with the density of LDL which aggregated to form cubes or stacks with distinct periodicity.

In confirming the above findings we have isolated by molecular sieve chromatography the two lipoproteins found in abetalipoproteinaemic plasma, and have found evidence to suggest that they may be interconvertible in vitro. We have also examined the metabolism of ${ }^{125} \mathrm{I}$-apolipoprotein A-I (the major HDL apoprotein) in an abetalipoproteinaemic subject in order to determine the cause of the decreased plasma HDL concentration in the condition.

\section{Subjects}

\section{CONTROLS}

Ten healthy adults (five men and five women) consented to be control subjects in this study. None had clinical or biochemical evidence of cardiovascular, endocrine, hepatic, or renal disease and none was taking any drugs (including oral contraceptives). The biochemical status and apoA-I turnovers in these volunteers are presented elsewhere (Caslake et al., 1977). In this paper the data are summarised to enable the results in the abetalipoproteinaemic subject to be evaluated.

ABETALIPOPROTEINAEMIC SUBJECT

This patient, a 49-year-old woman of Jewish origin, had a long-standing history of malabsorption, 
anaemia, retinitis pigmentosa, and mild but progressive cerebellar ataxia consonant with a diagnosis of abetalipoproteinaemia. Her siblings and only child were clinically and biochemically normal; neither of her parents was available for study. Steatorrhoea, unresponsive to a gluten-free diet, was first noted in her infancy. Although this had diminished and the fat content of the stools was normal, continuing hypovitaminosis A suggested that underlying subclinical malabsorption persisted and might be contributing to her major problem of retinal degeneration. Acanthocytosis was a striking feature in the blood film and hypolipoproteinaemia was the major biochemical abnormality. After a 14hour fast $\beta$-quantification (Lipid Research Clinics Program, 1974) of her plasma gave the following results: total plasma cholesterol $2.58 \mathrm{mmol} / 1(100$ $\mathrm{mg} / 100 \mathrm{ml}$ ), total plasma triglyceride unmeasurably low, VLDL cholesterol $0.10 \mathrm{mmol} / 1(3.9 \mathrm{mg} / 100$ $\mathrm{ml})$, LDL cholesterol $0.31 \mathrm{mmol} / \mathrm{l}(12.1 \mathrm{mg} / 100 \mathrm{ml})$, HDL cholesterol $2 \cdot 20 \mathrm{mmol} / \mathrm{l}(85 \cdot 8 \mathrm{mg} / 100 \mathrm{ml})$. Apolipoprotein B was not detectable in the plasma by radioimmunoassay (Bedford et al., 1976) even when the plasma was undiluted.

\section{Material and methods}

Details of the reagents and techniques used have been previously reported (Shepherd et al., 1977a; Caslake et al., 1977). Apolipoprotein A-I was isolated from normal HDL by column chromatography, labelled with ${ }^{125} \mathrm{I}$ using the McFarlane procedure, and incorporated into the abetalipoproteinaemic plasma lipoprotein fraction of $\mathrm{d}<1.225 \mathrm{~kg} / \mathrm{l}$ by in-vitro incubation at an apoprotein/lipoprotein molar ratio of less than 1:200 (assuming a lipoprotein apoprotein mass of 125000 ). The $125 \mathrm{I}$-apoA-I/HDL was separated from free ${ }^{125} \mathrm{I}$-apoA-I by ultracentrifugal flotation at $\mathrm{d}=1.225 \mathrm{~kg} / \mathrm{l}$ and sterilised by filtration $(0.22 \mu$ Millipore filters) before injection into the abetalipoproteinaemic patient. The kinetic parameters of the ${ }^{125} \mathrm{I}$-apoA-I lipoprotein complex were determined as described before (Caslake et al., 1977; Packard et al., 1976).

The chromatographic behaviour of the abetalipoproteinaemic plasma lipoproteins was examined using columns containing $6 \%$ agarose beads (Shepherd, 1976). Estimations of cholesterol (Annan and Isherwood, 1969), triglyceride (Kessler and Lederer, 1965), phospholipid (Bartlett, 1959), and protein (Lowry et al., 1951) were made by standard procedures. Plasma apoA-I was measured by electroimmunoassay (Shepherd et al., 1977a) at daily intervals throughout the turnover study. The withinand between-batch coefficients of variation for the assay were $3.6 \%(n=15)$ and $4.8 \%(n=19)$ respectively.
KINETIC ANALYSIS

Throughout the kinetic study the patient was maintained on her regular diet, which stabilised her total plasma cholesterol value (equivalent in this patient to HDL cholesterol). The mean daily plasma cholesterol ( \pm ISD) over the 14-day study period was $1.9 \pm 0.17 \mathrm{mmol} / 1(74.1 \pm 6.6 \mathrm{mg} / 100 \mathrm{ml})$. The kinetic data derived from the ${ }^{125} \mathrm{I}$-apoA-I turnover were processed by the mathematical procedure of Matthews (1957) which can calculate the fractional catabolic rate (FCR) of the apoprotein (that is, the fraction of the intravascular pool catabolised per day) and the distribution of the label between intravascular and extravascular body pools. From knowing the intravascular apoA-I pool (the product of the plasma apoA-I concentration and the plasma volume, determined by isotope dilution (Caslake $e t$ al., 1977)) the absolute rate of catabolism (ACR) of the apoprotein was determined. This was equivalent, under steady-state conditions, to the apoprotein synthetic rate.

To provide a check on the FCR determined by Matthews's (1957) mathematical procedure an independent assessment of this parameter was made by the method of Berson and Yalow (1957). Sequential 24-hour urine collections, whose completeness was ensured by measuring creatinine excretion, were made throughout the study using $10 \%$ thymol in isopropanol as preservative $(5 \mathrm{ml} / 24$-hour urine collection). The FCR was calculated daily from the total radioactivity excreted in the urine during each 24-hour period and from the mean plasma radioactivity at that time.

\section{Results}

KINETIC ANALYSIS OF

ABETALIPOPROTEINAEMIC HDL

The metabolism of apoA-I in the plasma of the abetalipoproteinaemic patient was determined as described previously (Caslake et al., 1977). ${ }^{125}$ IapoA-I formed a stable complex in vitro with the abetalipoproteinaemic lipoproteins isolated by flotation at $1.225 \mathrm{~kg} / \mathrm{l}$. When the apoprotein/lipoprotein molar ratio was less than 1:200 (assuming a lipoprotein apoprotein mass of 125000 daltons) about $70 \%$ of the apoprotein was assimilated into the lipoproteins, and after injection into the patient's vascular compartment the 125I-apoA-I remained associated with a plasma component of density less than 1.225 $\mathrm{kg} / \mathrm{l}$ (that is, with lipoproteins). Agarose gel filtration of the total plasma lipoprotein fraction on days 1 and 6 of the study showed that the radioactivity coeluted with each lipoprotein peak on the chromatographic profile.

The plasma clearance curves of the ${ }^{125} \mathrm{I}$-apoA-I in 


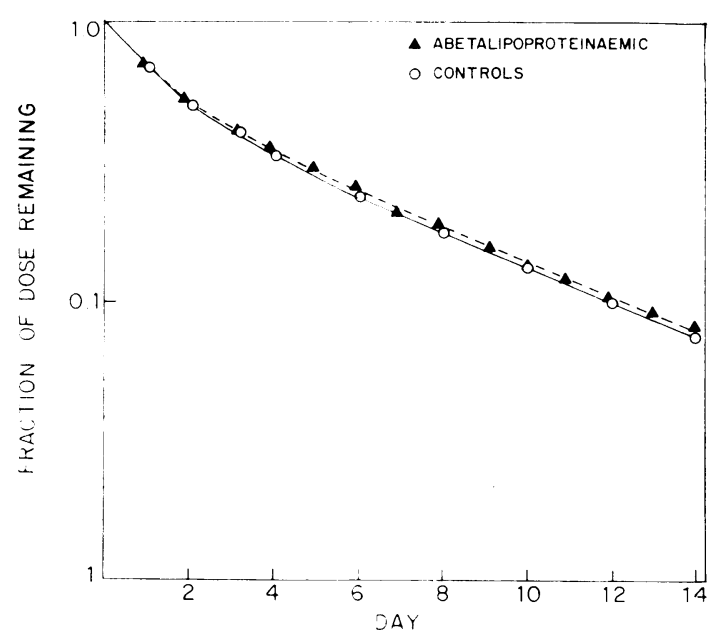

Fig. 1 Plasma clearance curves of ${ }^{125}$ I-apo A-I intercalated into control $(\bigcirc-\bigcirc)$ and abetalipoproteinaemic $H D L(\mathbf{\Delta}-\mathbf{\Delta})$ and reinjected into donors. Control curve indicates the mean apoA-I clearance in 10 subjects.

the abetalipoproteinaemic patient and control subjects are shown in Fig. 1 and are consistent with the premise that the radioactive apoprotein remained bound throughout its biological lifetime to a high molecular weight component such as HDL. Both profiles conform best to a two-compartment model comprising a vascular and extravascular space.

Application of Matthews's (1957) analytical procedure to the data (Table 1) indicates that the inter-compartmental distribution of the isotope in the abetalipoproteinaemic and control subjects is similar, about $70 \%$ of the radioactivity being intravascular. Moreover, the fraction of the intravascular pool catabolised per day does not differ significantly in both groups and corresponds to about $25 \%(22 \%$ and $28 \%$ in the abetalipoproteinaemic by calculation and from urine/plasma radioactivity ratios respectively, $26 \%$ in controls). However, in the abetalipoproteinaemic patient the intravascular
apoA-I pool is reduced to $57 \%$ of the control value. Consequently, the synthetic rate of apoA-I in the abetalipoproteinaemic patient is also significantly reduced, corresponding to an apoA-I production rate of $8.0 \mathrm{mg} / \mathrm{kg} /$ day (compare the control value of $12.0 \mathrm{mg} / \mathrm{kg} /$ day).

PHYSICOCHEMICAL CHARACTERISATION OF ABETALIPOPROTEINAEMIC PLASMA

LIPOPROTEINS

The lipoprotein from $6.0 \mathrm{ml}$ of fasting normal plasma isolated by ultracentrifugation at $\mathrm{d}=1.225 \mathrm{~kg} / \mathrm{l}$ and chromatographed on a $6 \%$ agarose gel (Bio-Gel A5m, 200-400 mesh, exclusion limit $=5 \times 10^{6}$ (BioRad Laboratories, Richmond, CA)) gave the characteristic triple peak elution profile (Fig. 2A) in which VLDL, LDL, and HDL elute sequentially from the column (Rudel et al., 1974). In contrast, the abetalipoproteinaemic lipoprotein profile (Fig. 2B) contained two peaks. The first of these (peak I) appeared in the exclusion volume of the gel and consequently contained material with a molecular weight equal to or greater than $5 \times 10^{6}$. The second peak (peak II) eluted five fractions after the ${ }^{125}$ I-LDL marker and 11 fractions before normal HDL. Consequently, the particles in this peak are of larger size or different shape than HDL.

Chemical and immunochemical analysis of the peak I and peak II components (Table 2) revealed a fundamental compositional similarity between them. Each contained about $44 \%$ protein, $23 \%$ cholesterol, and $33 \%$ phospholipid (as phosphatidyl choline). Triglyceride was not present in measurable amounts.

Using monospecific antibodies to the major HDL apoproteins it was found by the double immunodiffusion technique of Ouchterlony (1964) that each peak contained apoA-I, apoA-II, apoC-II, and apoC-III immunoreactivity. ApoB was absent from the lipoproteins and apoC-I was not assayed. The chemical and immunochemical similarity of the material in peaks I and II suggested that one may be derived from the other as a result of aggregation or disaggregation. This proposal was supported by the finding that peak I material, after concentration in a

Table 1 Kinetic parameters of ${ }^{125}$ I-apoA-I metabolism in control and abetalipoproteinaemic subjects. Control values are the means from subjects of a previous study (Caslake et al., 1977)

\begin{tabular}{|c|c|c|c|c|c|c|c|c|}
\hline \multirow[t]{2}{*}{ Subject } & \multirow{2}{*}{$\begin{array}{l}\text { Plasma } \\
\text { apoA-I } \\
(m g / 100 \mathrm{ml})\end{array}$} & \multirow{2}{*}{$\begin{array}{l}\text { Intravascular } \\
\text { apoA-I pool } \\
(\mathrm{mg})\end{array}$} & \multirow[t]{2}{*}{$\begin{array}{l}\% \text { apoA-I } \\
\text { intravascular }\end{array}$} & \multirow{2}{*}{$\begin{array}{l}\text { apoA-I } \\
\text { half life } \\
\text { (days) }\end{array}$} & \multicolumn{2}{|c|}{$\begin{array}{l}\text { Fractional catabolic rate } \\
\text { (pools/day) }\end{array}$} & \multirow{2}{*}{$\begin{array}{l}\text { apoA-I } \\
\text { catabolised } \\
\text { per day } \\
(\mathrm{mg})\end{array}$} & \multirow{2}{*}{$\begin{array}{l}\text { Absolute } \\
\text { catabolic } \\
\text { rate } \\
(\mathrm{mg} / \mathrm{kg} / \mathrm{day})\end{array}$} \\
\hline & & & & & Calculated & From $U / P$ ratios & & \\
\hline \multirow{3}{*}{$\begin{array}{l}\text { Controls (mean of } 5 \\
\text { males } \pm \text { ISD) } \\
\text { Controls (mean of } 5 \\
\text { females } \pm \text { ISD) } \\
\text { Abetalipoproteinaemic } \\
\text { female }\end{array}$} & $105 \div 19$ & $3267 \pm 676$ & $69 \cdot 8 \pm 3 \cdot 6$ & $4.46 \div 0.45$ & $0.27 \div 0.03$ & $\cdots$ & $831 \pm 103$ & $12 \cdot 1 \quad 1 \cdot 6$ \\
\hline & $111 \div 14$ & $2769 \pm 478$ & $69 \cdot 4 \div 2 \cdot 7$ & $4 \cdot 64 \pm 0.7$ & $0.25: 0.03$ & - & $709 \pm 175$ & $11 \cdot 9 \div 2 \cdot 4$ \\
\hline & $89=7$ & 1709 & 70 & $4 \cdot 65$ & 0.22 & $0.28=0.06$ & 382 & $8 \cdot 0$ \\
\hline
\end{tabular}



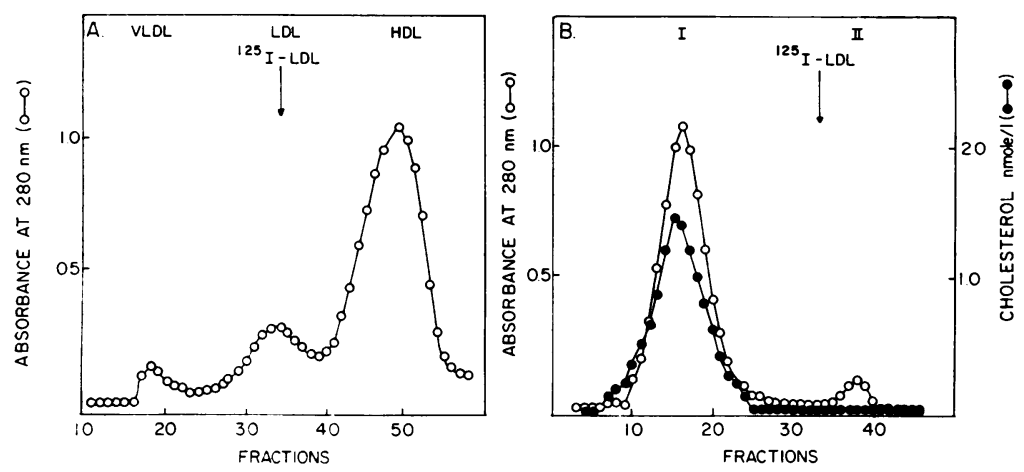

Fig. 2 Elution profile from $6 \%$ agarose gel of plasma lipoproteins from $(A)$ control and $(B)$ dyslipoproteinaemic subject. Fosition of ${ }^{125}$ I-LDL marker, added to each sample before chromatography, arrowed.

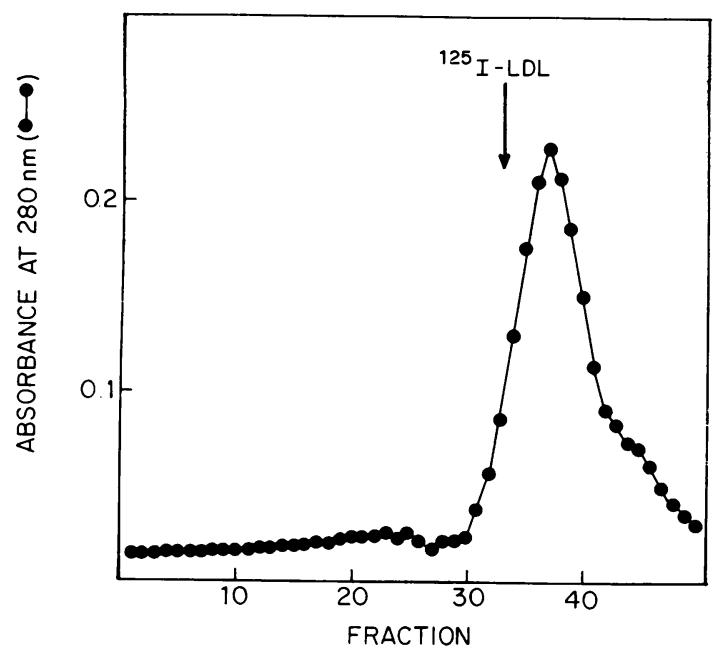

Fig. 3 Rechromatography of peak I from Fig. 1 on $6 \%$ agarose gel.

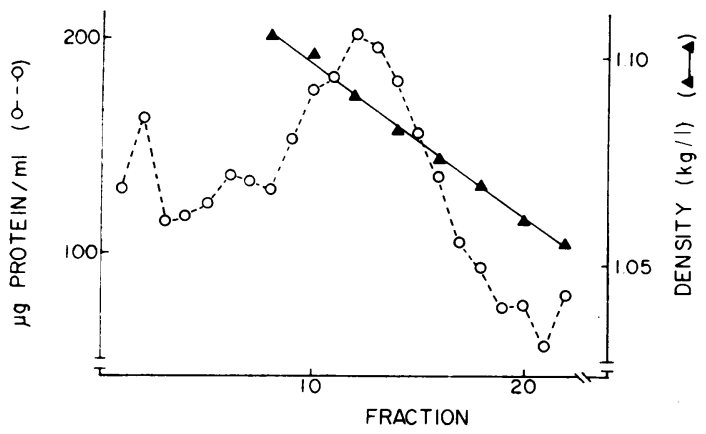

Fig. 4 Isopyknic centrifugation of peak II from Fig. 3 on $\mathrm{KBr}$ gradient $(d=1 \cdot 050-1 \cdot 130 \mathrm{~kg} / \mathrm{l})$.

Minicon B15 cell (Amicon Corp, Lexington, Mass), rechromatographed in the position of peak II (Fig. 3 ). The density of this rechromatographed material

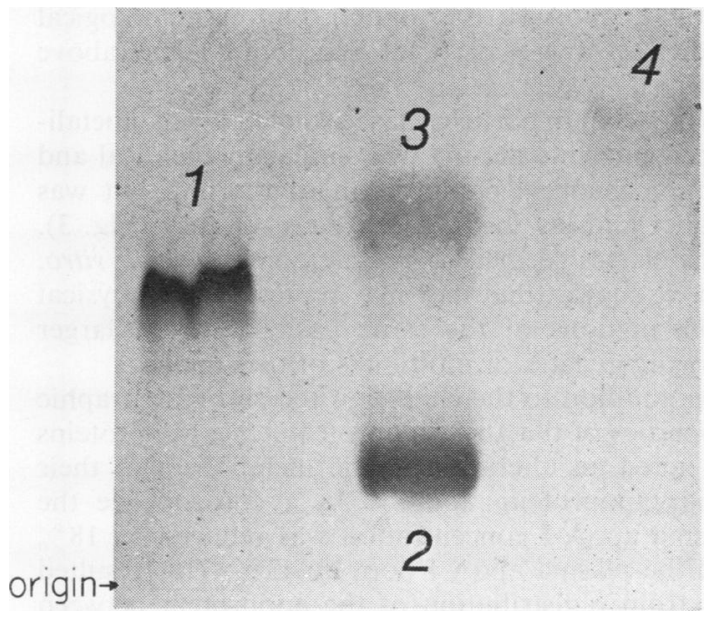

Fig. 5 Agarose gel electrophoretogram of control and abetalipoproteinaemic lipoproteins. (1) Control VLDL. (2) Control LDL. (3) Control HDL. (4) Peak II from abetalipoproteinaemic plasma (see Fig. 3).

was measured by isopyknic centrifugation in $\mathrm{KBr}$ solution over the density range $1 \cdot 050-1 \cdot 130 \mathrm{~kg} / \mathrm{l}$ (Fig. 4). The lipoprotein density covered a broad range, with a maximum value at $1.090 \mathrm{~kg} / \mathrm{l}$. Electrophoretic analysis (Fig. 5) of the same material on an agarose support (Corning ACI, Palo Alto, CA) showed that it migrated ahead of the HDL moiety of normal plasma.

\section{Discussion}

The metabolic defect in abetalipoproteinaemia is complex and affects all classes of plasma lipoproteins. As a result the elution profile obtained by molecular sieve chromatography of abetalipoproteinaemic plasma differs radically from the normal. In this study two lipoprotein classes were isolable on the basis of size. The first of these (peak I, Fig. 2B) had a 
Table 2 Chemical and immunochemical characterization of abetalipoproteinaemic plasma lipoproteins. Peaks I and II were isolated by gel filtration of lipoproteins as described in Fig. 1

\begin{tabular}{|c|c|c|c|c|c|c|c|c|}
\hline & \multicolumn{4}{|c|}{ Percentage: } & \multicolumn{4}{|c|}{ Apoproteins detected } \\
\hline & Protein & Cholesterol & Phosphoiipid & Triglyceride & $A-I$ & $A-I I$ & $C-I I$ & $C \cdot I I I$ \\
\hline Peak I & 44 & 23 & 33 & Not detected & & & & \\
\hline Peak I & 43 & 21 & 36 & Not detected & & & & $\therefore$ \\
\hline
\end{tabular}

molecular weight of $5 \times 10^{6}$ or more and may correspond to a particle of similar size which was isolated by ultra-centrifugal flotation at a density of $1.063 \mathrm{~kg} / \mathrm{l}$ (Kostner et al., 1974). This material was found by others (Gotto et al., 1971; Scanu et al., 1974) to have all the major HDL apoproteins (apoA-I, apoA-II, and apoC). Our immunological studies of these particles corroborate the above findings.

The second particle class isolated from abetalipoproteinaemic plasma was similar in chemical and immunochemical composition to the first but was smaller and lay in the HDL density range (Fig. 3). Both classes seemed to be interconvertible in vitro, and we suggest that they may represent two physical conformations of the same basic unit, the larger being aggregates or multimers of the smaller.

In addition to the change in the chromatographic properties of the abetalipoproteinaemic lipoproteins we noted an alteration in the metabolism of their major apoprotein, apoA-I. As a consequence the plasma apoA-I concentration was reduced by $18 \%$ and the plasma apoA-I pool by $43 \%$. This resulted not from redistribution of the apoprotein between intravascular and extravascular compartments or from an increase in the fractional catabolic rate of the apoA-I but rather from a $33 \%$ decrease in apoA-I synthesis. The cause of this decrease is not yet clear. However, Windmueller and Spaeth (1972) showed that apoA-I synthesis occurs in part in the intestine. We observed (Shepherd et al., 1977b) that the rate of synthesis of this apoprotein is affected by dietary fat, presumably at its site of absorption in the gut. We believe that malabsorption of fat, characteristic of abetalipoproteinaemia and a feature of the disease in our patient, may play an important part in reducing intestinal apoA-I synthesis in this condition.

This work was supported by a grant from the Scottish Hospital Endowments Research Trust.

\section{References}

Annan, W., and Isherwood, D. M. (1969). An automated method for the direct determination of total serum cholesterol. Journal of Medical Laboratory Technology, 26, 202-211.
Bartlett, G. R. (1959). Phosphorus assay in column chromatography. Journal of Biological Chemistry, 234, 466-468.

Bassen, F. A., and Kornzweig, A. L. (1950). Malformation of the erythrocytes in a case of atypical retinitis pigmentosa. Blood, 5, 381-387.

Bedford, D. K., Shepherd, J., and Morgan, H. G. (1976). Radioimmunoassay for human plasma apolipoprotein B. Clinica Chimica Acta, 70, 267-276.

Berson, S. A., and Yalow, R. S. (1957). Distribution and metabolism of ${ }^{131} \mathrm{I}$-labelled proteins in man. Federation Proceedings, 16, 135.

Caslake, M. J., Farish, E., and Shepherd, J. (1977). Metabolism of apolipoprotein A-I in healthy young adults. Metabolism. (In press).

Forte, T., and Nichols, A. V. (1972). Application of electron microscopy to the study of plasma lipoprotein structure. Advances in Lipid Research, 10, 1-41.

Fredrickson, D. S., Gotto, A. M., and Levy, R. I. (1972). Familial lipoprotein deficiency. In The Metabolic Basis of Inherited Disease, edited by J. B. Stanbury, J. B. Wyngaarden, and D. S. Fredrickson, 3rd edition, pp. 493-530. McGraw-Hill, New York.

Fredrickson, D. S., Levy, R. I., and Lees, R. S. (1967). Fat transport in lipoproteins-an integrated approach to mechanisms and disorders. New England Journal of Medicine, 276, 34-44, 94-103, 148-156, 21 5-225, 273-281.

Frézal, J., Rey, J., Polonovski, J., Lévy, G., and Lamy, M. (1961). L'absence congénitale de $\beta$-lipoprotéines: étude de l'absorption das graisses après exsanguinotransfusion: mesure de la demi-vie des $\beta$-lipoprotéines injectées. Revue Française d'Études Cliniques et Biologiques, 6, 677-683.

Gotto, A. M., Levy, R. I., Johr, K., and Fredrickson, D. S. (1971). On the protein defect in abetalipoproteinemia. New England Journal of Medicine, 284, 813818.

Jones, J. W., and Ways, P. (1967). Abnormalities of high density lipoproteins in abetalipoproteinemia. Journal of Clinical Investigation, 46, 1151-1161.

Kayden, H. J. (1972). Abetalipoproteinaemia. Annual Review of Medicine, 23, 285-296.

Kessler, G., and Lederer, H. (1965). Fluorimetric measurement of triglycerides. In Automation in Analytical Chemistry (Technicon Symposium), edited by L. T. Skeggs, pp. 341-344. Mediad Inc., White Plains, N.Y.

Kostner, G., Holasek, A., Bohlmann, H. G., and Thiede, H. (1974). Investigation of serum lipoproteins and apoproteins in abetalipoproteinaemia. Clinical Science and Molecular Medicine, 46, 457-468.

Lipid Research Clinics Program Manual of Laboratory 
Operations (1974). DHEW Publication number (NIH) 75-628.

Lowry, O. H., Rosebrough, N. J., Farr, A. L., and Randall, R. J. (1951). Protein measurement with the Folin phenol reagent. Journal of Biological Chemistry, 193, 265-275.

Matthews, C. M. E. (1957). The theory of tracer experiments with ${ }^{131} \mathrm{I}$-labelled plasma proteins. Physics in Medicine and Biology, 2, 36-53.

Ouchterlony, Ö. (1964). Gel diffusion Techniques. In Immunological Methods, edited by J. F. Ackroyd, pp. 55-78. Blackwell, Oxford.

Packard, C. J., Third, J. L. H. C., Shepherd, J., Lorimer, A. R., Morgan, H. G., and Lawrie, T. D. V. (1976). Low density lipoprotein metabolism in a family of familial hypercholesterolaemic patients. Metabolism, 25, 995-1106.

Rudel, L. L., Lee, J. A., Morris, M. D., and Felts, J. M. (1974). Characterization of plasma lipoproteins separated and purified by agarose-column chromatography. Biochemical Journal, 139, 89-95.

Scanu, A. M., Aggerbeck, L. P., Kruski, A. W., Lim,
C. T., and Kayden, H. J. (1974). A study of the abnormal lipoproteins in abetalipoproteinemia. Journal of Clinical Investigation, 53, 440-453.

Shepherd, J. (1976). Diagnosis of dyslipoproteinaemia by molecular sieve chromatography. Clinica Chimica Acta, 69, 161-173.

Shepherd, J., Gotto, A. M., Taunton, O. D., Caslake, M. J., and Farish, E. (1977a). The in vitro interaction of human apolipoprotein A-I and high density lipoproteins. Biochimica et Biophysica Acta. (In press).

Shepherd, J., Packard, C. J., Patsch, J. R., Gotto, A. M., and Taunton, O. D. (1977b). Effect of saturated versus polyunsaturated fat on high density lipoprotein metabolism in normal subjects. Clinical Research, 25, 499A.

Sturman, R. M. (1968). The Bassen-Kornzweig Syndrome: 18 years in evolution. Journal of Mount Sinai Hospital, 35, 489-517.

Windmueller, H. G., and Spaeth, A. E. (1972). Fat transport and lymph and plasma lipoprotein biosynthesis by isolated intestine. Journal of Lipid Research. 13, 92-105. 